\title{
Liquid Chromatography-Mass Spectrometry and Its Applications: A Brief Review
}

\author{
Nikalje Anna Pratima* and Ramesh Gadikar \\ Department of Pharmaceutical Chemistry, YB Chavan College of Pharmacy, India
}

Received: 卧 January 06, 2018; Published: 海January 24, 2018

*Corresponding author: Nikalje Anna Pratima, Department of Pharmaceutical Chemistry, YB Chavan College of Pharmacy, Dr. Rafiq Zakaria Campus, Aurangabad 431001, Maharashtra, India

\begin{abstract}
The Liquid Chromatography-Mass Spectrometry (LC-MS) is a powerful analytical technique with very high sensitivity and specificity. LC-MS is combination of Liquid Chromatography (LC) and Mass Spectrometry (MS). With the Liquid Chromatography (LC) the separation of components can be done and then the sample eluents from LC are transferred into Mass Spectrometry (MS) where the detection, identification and determination of masses of components can be done in presence of other components. LC-MS is used in determination, of pharmaceutical drug substances, intermediates and its related compounds for quantitative and qualitative purpose. LC-MS is used most significantly in in-vitro dissolution, bio-equivalence, bioavailability and metabolite studies. Also LC-MS is used in basic research, agrochemical, forensic laboratories and food industries .In this article principle of LC-MS, instrumentation and its applications are briefly discussed.
\end{abstract}

Keywords: Liquid chromatography (LC); Mass spectrometry (MS); High Performance Liquid Chromatography (HPLC); Liquid Chromatography-Mass Spectrometry (LC-MS)

\section{Introduction}

\section{Liquid Chromatography-Mass Spectrometry (LC-MS)}

The High Performance Liquid chromatography (HPLC) is one of most common analytical technique used in pharmaceutical industry for determination and quantification of drug substances and its related substances. Due to high reproducibility and accuracy, HPLC is routinely used in pharmaceutical, chemical and pesticide industries.

The Liquid Chromatography-Mass Spectrometry (LC-MS) is hyphenated analytical technique which is combination of Liquid Chromatography (LC) and Mass Spectrometry (MS). HPLC (LC) separates the components of mixtures by passing through chromatographic column. Generally, the separated components cannot be positively identified LC alone. Mass Spectrometry is also used for identification of unknown compounds, known compounds and to elucidate the structure. Mass spectrometry is alone not good for identifying mixtures because mass spectrum mixture is actually complex of overlapping spectra from separated individual components. It is difficult to connect Liquid chromatography (LC) with Mass spectrometry (MS). An interface is used to transfer the liquid eluents from LC to MS.LC-MS is more significantly used in invite dissolution, bioavailability, bioequivalence and pharmacodynamics studies [1]. Preparative LC-MS systems can be used for rapid mass-directed purification of specific substances from such mixtures that are important in basic research, pharmaceutical, agrochemical, food and other industries [2,3].

\section{Instrumentation}

\section{Liquid chromatography-mass spectrometry (LC-MS)}

The Liquid Chromatography-Mass Spectrometry (LC-MS) is combination of Liquid Chromatography and Mass Spectrometry which is used with separation power of HPLC with detection power of Mass Spectrometry (MS). The schematic block diagram of LC-MS is shown in below figure 1. The different parts of LC-MS instrument are listed as below.

a. Liquid Chromatography (LC)

b. Mass Spectrometry (MS)

Liquid Chromatography (HPLC): The Liquid Chromatography (LC) is a high performance liquid chromatography in which separation of components of mixture can be carried out by using liquid mobile and solid stationary phase. There are different types of 
chromatographylike normal phase liquid chromatography, Reversed phase chromatography, Ion-exchange liquid chromatography, Chiral separation and affinity liquid chromatography [3]. By using different packing of columns with high efficiency small amount of complex mixture can be separated. The components of HPLC are listed below:

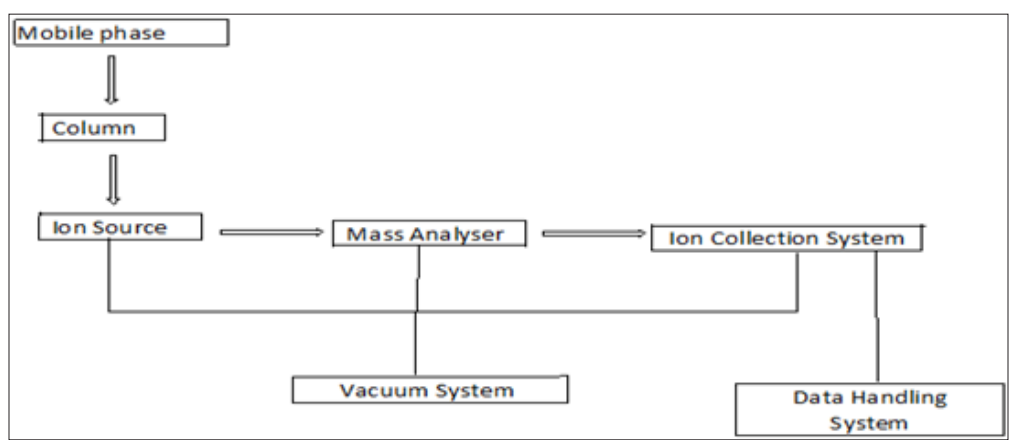

Figure 1: Schematic Block Diagram of LC-MS System.

a. Pump: It consists of material which is inert towards solvents or any mixed composition of aqueous buffer and organic solvents. It delivers high volume of mobile phase up to $10 \mathrm{~mL} / \mathrm{min}$. There are three major types of pumps are used i.e. reciprocating pump, Syringe pumps and constant pressure pumps.

b. Sample injector: It is used to introduce sample volume into the chromatographic system. Generally sample volume from $1 \mu \mathrm{L}$ to $100 \mu \mathrm{L}$ can be injected. The injection volume can be increase by injector loop up to $2 \mathrm{~mL}$ volume. There are two major types of injectors used i.e. Automatic injectors and Manual injectors. Automatic injectors are more comfortable and user friendly and are more accurate and precise as compare to manual injectors [3].

c. Columns: It is stationary phase which consists of silica material in combination with carbon chain. Generally the column length used is about $50 \mathrm{~mm}$ to $300 \mathrm{~mm}$. The columns used in HPLC are consists of Octadecyl (C18), Octyl (C8), Cyano, Amino, Phenyl packing's. The columns are used on the basis of nature of compounds to be separated [4].

d. Detectors and recorder: The detectors is most important part of HPLC .There are different types of detectors used are UV-Visible detectors, PDA detectors, Refractive index (RI) detectors, Electrochemical detector, Fluorescence detectors and conductivity detectors. The signal received from detector can be recorded as peak and respective data can be stored in a software.

Mass spectrometry: Mass Spectrometry is analytical technique based on the measurement of the mass to charge ratio of ionic species related to the analyte under the investigation.MS can be used to determine the molecular mass and elemental composition of an analyte as well as in depth structural elucidation of the analyte [5]. In LC-MS there are two key components, ionization source and Interfaces. Below listed are the different components of Mass spectrometers as below. a. Ionization Sources and Interfaces

b. Mass Analysers

Ionization/Ion Source and Interfaces: The Liquid chromatography separates mixture of components which are in liquid form, usually contains methanol, acetonitrile and water. This liquid containing mixture of components is transferred into the ion source of mass spectrometer. As ion source is under high vacuum. Due to the difference in the pressure it is difficult to mass to vaporize the liquid drops without losing mixture of components. Hence interfaces are used to resolve this problem. The different types of interfaces commonly used in mass spectrometer are described as below.

a. Direct liquid Introduction (DLI): The ionization in Direct Liquid Introduction (DLI) is generally accomplished by vaporizing solvent as a chemical ionization and reagent gas. Both the normal and reverse phase solvent system have been used. Reverse phase solvents used are methanol/water, acetonitrile/ water mixture up to $60 \%$ water. In general buffer with salts are not allowed as there is chance of capillaries to plug when heated.

The operation of Direct Liquid Introduction (DLI) is combination of thermal energy and liquid flow rate. The liquid enters the interface at limited flow rate only. The analyte ions produced with the help of thermal energy then transferred into ion source through capillary inlet or pinhole diaphragm $[6,7]$.

b. Atmospheric-Pressure Ionization (API): In Atmospheric-pressure ionization (API) contains three major steps i.e. Nebulisation, Evaporation and Ionization. There are two main modes of API are Electrospray Ionization (ESI) and Atmospheric-pressure ionization (APCI). In Atmosphericpressure ionization (API), when stream of liquid (solvent) containing a sample is passed through narrow capillary tube and nebulized at large chamber, mist of small droplets is produced.The ionization process takes place and the 
proportion of droplets carry an excess of positive or negative electric charge .In large heating chamber the evaporation of solvent takes place. The solvent evaporates from the droplets to form smaller and smaller. The collision takes place between the molecules and ions. The resulting ions then passed through capillary into mass analyser $[2,8]$.

The Atmospheric-pressure ionization (API) is technique used for wide range of polar and non-polar analytes of moderate molecular weights.

c. Electrospray Ionization (ESI): The Electrospray Ionization (ESI) is most useful ion source developed by Fenn and his colleague's. In Electrospray Ionization (ESI) the liquid sample passed through a stain steel capillary tube which is maintained at high positive or negative electric potential about $3-5 \mathrm{kV}$ [1]. Due to this the charged droplets are formed at the capillary tip which are then undergoes vaporization process. The solvent gets evaporated from droplets, and undergoes reduction in size and surface charge increases. The collision takes place until the highly charged droplets are converted into gas phase ions. These gas-phase ions pass through the capillary sampling orifice into the low pressure region of the ion source [9].

The major advantage of ESI is that the ions are multiply charged, the number of charges increased by 1 to 3 for a molecule $1000 \mathrm{Da}$ or above $50000 \mathrm{Da}$. This yields an $\mathrm{m} / \mathrm{z}$ ratio that is always below 2000. LC-MS with an Electro spray ionization (ESI) is used to measure the molecular weight of peptides, Proteins, Biological samples, Polymers, nucleotides, sugars and organometallics. It is also used frequently in Biological research and medical analysis [10]. The Schematic diagram of ESI is shown figure 2.

Figure 2: Electrospray ionization source.

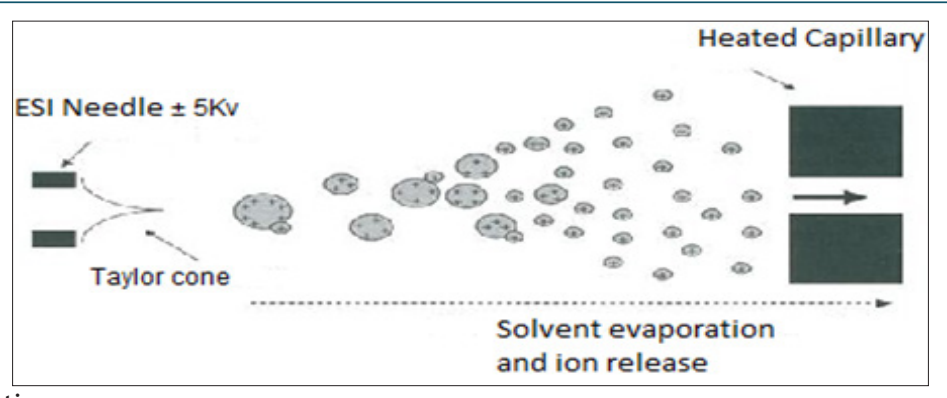

d. Atmospheric Pressure Chemical Ionization (APCI): The Atmospheric Pressure Chemical Ionization (APCI) include two major steps, evaporation /desolvations of analytes and charged transfer reaction in vapour phase to generate the vapour phase ions.

In Atmospheric Pressure Chemical Ionization (APCI) liquid (solvent) containing sample is nebulised through narrow capillary tube and nebulized into large chamber. In large heating chamber the evaporation of solvent takes place at atmospheric pressure and small droplets are produced. The ionization takes place. Generally ionization takes place at 250 to $400{ }^{\circ} \mathrm{C}$. The ions are then transfer the charges to molecules through chemical reactions. The resulting ions are pass through capillary orifice of mass analyser. It is widely used for less polar and non-polar analytes having moderate molecular weights [11].

e. Thermo spray and Plasma spray Ionization (TSPI):

The Thermo spray is used as both liquid inlet system as well as ionization source. Plasma spray is modification of thermo spray.

In Thermo spray the liquid sample solution is passed through capillary tube which is heated and which causes the evaporation of solvent. The charged droplets are formed. Due to evaporation of solvent the droplets becomes smaller and smaller. The density of electric charge on the surface of droplets increases. The resulting ions are then passed into mass analyser with electrostatic voltage system [8].

The Plasma spray itself does not produce ions but the ions produce in thermo spray, with the help of corona discharge or plasma the number of ions can be increased. The electric discharge induces the more ionization in the neutral molecules. This enhancement increases the ionization of molecule. The plasma spray technique is more sensitive and it is widely used for analysis in clinical and medicine [12].

f. Atmospheric pressure photo Ionization (APPI): In Atmospheric pressure photo Ionization (APPI), photons are used to excite and ionise the molecules. Atmospheric pressure photo Ionization (APPI) include mainly two steps i.e. excitation and ionisation of analyte from eluent.

Like atmospheric pressure chemical ionization (APCI) in Atmospheric pressure photo Ionization (APPI) the eluent from LC vaporize into gaseous phase. The APPI uses $\mathrm{Kr}$ lamp to produce photons. Kr lamp generates high energy photons which are used for excitation and ionization of molecules. The range of energy is selected to minimize the ionization of analytes. The ionized analytes are then transferred into capillary orifice into mass analyser $(\mathrm{m} / \mathrm{z})$.

This technique is useful for non-polar analytes which very much difficult to ionize with Electrospray Ionization (ESI) and Atmospheric Pressure Chemical Ionization (APCI) [13,14]. 
g. Particle Beam Ionization: The Browner and his colleagues has developed particle beam interface to separate the solvent from solute with minimum loss of solutes. The nebulization and evaporation process are like Thermo spray (TSP), Atmospheric pressure chemical ionization (APCI), Electrospray ionization (ESI) [15].

In this liquid separated from HPLC or LC, eluent is passed through narrow tube. The liquid is injected with helium gas, due to this the spray of liquid droplets are formed with high velocity. The liquid drops from nebulizer passes through heating chamber, where the solvent begins to evaporate and liquid droplets becomes smaller and smaller. The spray of liquid droplets exits through heating chamber as a particle beam. Then this beam passes through ionization chamber similarly like Electro spray Ionization (ESI) and Atmospheric Pressure Chemical Ionization (APCI) [2].

h. Continuous Flow Fast Atom Bombardment (FAB): The FAB is simple, high sensitivity technique of interface. In FAB liquid target is bombarded by fast atoms such as Argon(Ar) or xenon. The sample is dissolved in glycerol and spread on thin layer metal plate /probe. Then this probe is inserted into mass spectrometer and a beam of fast moving atoms bombards on probe and ionise the samples which then pass into mass analyser $(\mathrm{m} / \mathrm{z})$. FAB is used for large and thermally unstable molecules. It used for surfactants and proteins $[16,17]$.

Mass Analyser: After ionization the ions are transferred into mass Analyser where the separation of ions are done according to their mass to charge (m/z) ratio. Generally mass Analyser used is on its speed, time, rate and its reaction.

Below are the mass Analyser:

a. Quadrupole b. Time of flight

c. Ion trap

d. FTICR (Fourier transfer ion cyclotron resonance)

a. Quadrupole Mass Analyser: It is the most useful and commonly used mass Analyser. It consists of two plain of parallel rods which are located between an ion sources and a detector. The mass Analyser i.e. separation of ion according to their $\mathrm{m} / \mathrm{z}$ in either time or space [6].

The linear Quadrupole mass Analyser consists of four hyperbolic or cylindrical rods that are placed parallel in a radial array. Opposite rods are charged is a +ve or -ve direct current(DC) potential at which an oscillating radio frequency alternating current (RF) voltage is superimposed [18].

The combination of DC and RF applied to the rods, trajectories of the ions of one particular $\mathrm{m} / \mathrm{z}$ are stable these ions are transmitted towards detector. On the other hand ions of unstable $\mathrm{m} / \mathrm{z}$ are discharged on the rods.

Theions introduced into Quadrupole by mean of low accelerating potential. The ions are oscillating in plane perpendicular to the rod length as they trends through Quadruple filter.

Ions of carrying $\mathrm{m} / \mathrm{z}$ consequently be travelled towards detector by applying DC and RF voltage at constant ratio. The resolution depends on ratio of DC and RF potentials. Generally the Quadrupole is operated at $<4000 \mathrm{~m} / \mathrm{z}$ and scan speed up to $1000 \mathrm{~m} / \mathrm{z}$ passes. The unit mass resolution means that mass accurately is seldom better than $0.1 \mathrm{~m} / \mathrm{z}$ [19].

The RF values are generally in the range 1-2MHZ. The DC Voltage may be $1000 \mathrm{~V}$ and Maximum RF voltage is $6000 \mathrm{v}$. The schematic diagram of quadruple mass analyser is shown below figure 3 .

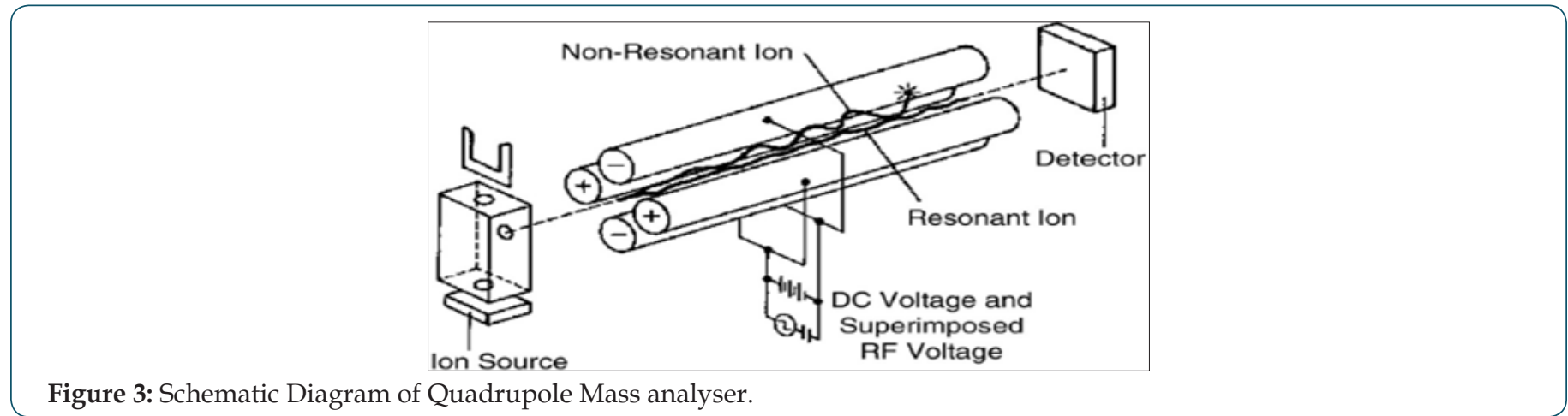

Figure 3: Schematic Diagram of Quadrupole Mass analyser.

\section{b. Time of Flight Analyser (TOF):}

The time Flight is most robust used for wide variety of ions sources and inlet systems. In this is no any magnetic field, maintenance and calibration it is just simple electrostatic and straight forward. The ions are extracted from source and subjected to an accelerating voltage. The time taken to travel the length of the drift or flight to be depends upon the mass of ion and its charge [20]. For single charged ions $(\mathrm{z}=1, \mathrm{~m} / \mathrm{z}=\mathrm{w})$ the time taken to reach the detector is proportional to mass of the ions. When the ions trends towards the detector the lighter ions will strikes the detector first [18].

Scanning of all the ions are detected simultaneously. The scanning the mass range is very rapid and can be used for very large $\mathrm{m} / \mathrm{z}$ values. The schematic diagram of Time Flight mass analyser is shown below figure 4 . 
Figure 4: Time of flight mass Analyser.

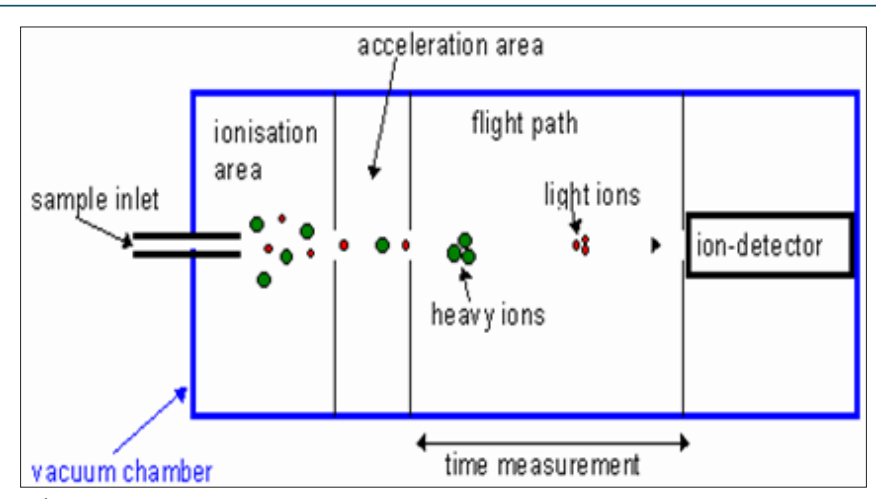

\section{c. Ions trap mass Analyser:}

Ion trap mass Analyser is high resolution, high sensitivity and multiple product ion scan capability.

A Quadrupole ion trap is a three dimensional ion trap. It consists of cylindrical ring electrode to which Quadrupole field is applied. Another two are end capped electrodes [21].

One end cap electrode has single small central aperture through which electrons or ions are introduced into the trap while other one has several apertures or holes through which ions are passed to a detector. A Helium bath gas is present in the trap to stabilize the ion trajectories. The collision takes place between helium bath gas and ions. Due to this the motion of ions increases the trapping efficiency of analyser. The ions are ejected from the trap on the basis of mass to charge $(\mathrm{m} / \mathrm{z})$ values to create the mass spectrum [22]. The schematic diagram shown below figure 5 .

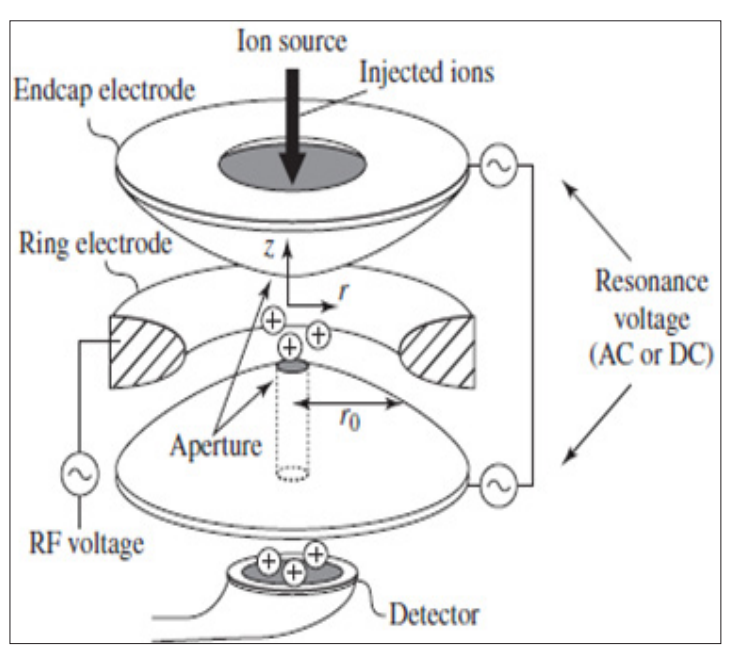

Figure 5: Ion Trap mass Analyser.

Table 1: Comparison between LC, MS and LC-MS. d. Fourier Transfer Ion Cyclotron Resonance (FT-ICR):

The Fourier transfer ion cyclotron resonance (FT-ICR) is most important mass analyser. The ions arrived from ionization source are passed into mass analyser where they are separated according to their $\mathrm{m} / \mathrm{z}$ ratio. The ions entered in chamber are trapped in circular orbits. The ions are accelerated by both electric field and magnetic field.

Due to this the ions get excited and generate time dependent current. The ions trapped separated according to mass to charge $(\mathrm{m} / \mathrm{z})$ ratios.

\section{Detectors}

The detector is an important tool of mass spectrometer that produces the current that is proportional to the number of ions strike it. Once the ions are formed passed from analyser they have to be detected and transformed into signal. Below listed are the type of detectors commonly used.

\section{Point Ion Collectors Detector:}

In this the ions collectors are placed at fixed point in mass spectrometer. All the ions are focused upon the detector situated at single point. The arrivals of ions can be recorded by the flow of electric current and the data can be recorded. The electric current flow is proportional to the ions arriving at point ion detector.

\section{Array Detector:}

An Array detector is collection of point collectors placed in plane. The ions are arrived at a point or across the plane in array detector. The ions with mass to charge $(\mathrm{m} / \mathrm{z})$ values are separated and are recorded along plane using point ion collector. Spatially differentiated ions with the mass range are detected simultaneously at the same time in array detector $[23,24]$ (Table 1 ).

\begin{tabular}{|c|c|c|}
\hline Liquid Chromatography (LC) & Mass Spectrometry (MS) & \\
\hline $\begin{array}{c}\text { 1. LC is an analytical chromato- graphic } \\
\text { technique that is useful for separatingions or } \\
\text { molecules that are dissolved in a solvent by } \\
\text { using liquid mobile phase and solid stationary } \\
\text { phase. }\end{array}$ & $\begin{array}{c}\text { 1. Mass spectrometry is an instrumental } \\
\text { technique in which sample is converted to } \\
\text { rapidly moving positive ions by electron } \\
\text { bombardment and charged particles are } \\
\text { separate according to their masses. }\end{array}$ & $\begin{array}{c}\text { 1. LC-MS is hyphenated analytical technique } \\
\text { which is combination of Liquid Chromatography } \\
\text { (LC) and Mass Spectrometry (MS) which is used } \\
\text { with separation power of HPLC with detection } \\
\text { power of Mass Spectrometry (MS).Separation } \\
\text { and quantitation of components can be done. }\end{array}$ \\
\hline
\end{tabular}




\begin{tabular}{|c|c|c|}
\hline $\begin{array}{l}\text { 2. In LC, Substances will move with the mobile } \\
\text { phase at different rate depending upon their } \\
\text { partition or adsorption. }\end{array}$ & $\begin{array}{l}\text { 2. In MS, the components can be converted into } \\
\text { gas phase ions and separates the ions in time } \\
\text { or space according to mass to charge ratios. } \\
\text { Measures the quantity of ions of each mass to } \\
\text { charge ratio. }\end{array}$ & $\begin{array}{l}\text { 2. In LC-MS, the separated components from LC } \\
\text { can be transferred into mass spectrometer with } \\
\text { the interfaces. Separation and determination of } \\
\text { relative atomic masses or molecular masses can } \\
\text { be performed simultaneously. }\end{array}$ \\
\hline $\begin{array}{l}\text { 3. This technique is used for chemistry and bio- } \\
\text { chemistry research analyzing complex mixtures. }\end{array}$ & $\begin{array}{l}\text { 3. Elucidation of the structure of the organic and } \\
\text { biological molecules. }\end{array}$ & $\begin{array}{l}\text { 3.Used in Pharmacokine-tics, Bioavailability and } \\
\text { bioequivalence studies. }\end{array}$ \\
\hline $\begin{array}{l}\text { 4. Used to quantify and separation of drug } \\
\text { substances and drug products. }\end{array}$ & $\begin{array}{l}\text { 4. Determination of mole- cular mass of } \\
\text { peptides, proteins etc. }\end{array}$ & 4. Used in metabolite studies, forensic studies. \\
\hline $\begin{array}{l}\text { 5. It is used in pharma- ceutical, agrochemical } \\
\text { and pesticide industries. }\end{array}$ & $\begin{array}{l}\text { 5. Monitoring gases in patients breathe during } \\
\text { surgery. }\end{array}$ & $\begin{array}{l}\text { 5. For determination of assays of drug } \\
\text { substances. }\end{array}$ \\
\hline $\begin{array}{l}\text { 6. Needs a small sample with a high accuracy } \\
\text { and precise. }\end{array}$ & 6. It is highly sensitive and accurate. & 6. It is highly sensitive and specificity technique. \\
\hline
\end{tabular}

\section{Applications}

\section{Application of LC/ESI-MS in In forensic sciences}

LC-MS is used for determination of toxicity, in drug analysis and also in trace analysis. By using small amount of sample the toxins in different material can be determined with LC-MS. Any toxic metabolites in food or beverages can be determined by using LC-MS. E.g. Identification of detergent added into orange juice can be determined by analysing by the juice and detergent sample. The standard surfactant alkyl diphenylether sulphonic acid is used. Both juice and detergent samples are analysed in same chromatographic conditions. The mass chromatograms and mass spectra obtained from the juice and detergent samples are identical with the reference spectra of standard surfactant (alkyl diphenyl ethersulphonic acid) $[25,26]$ (Figure 6).

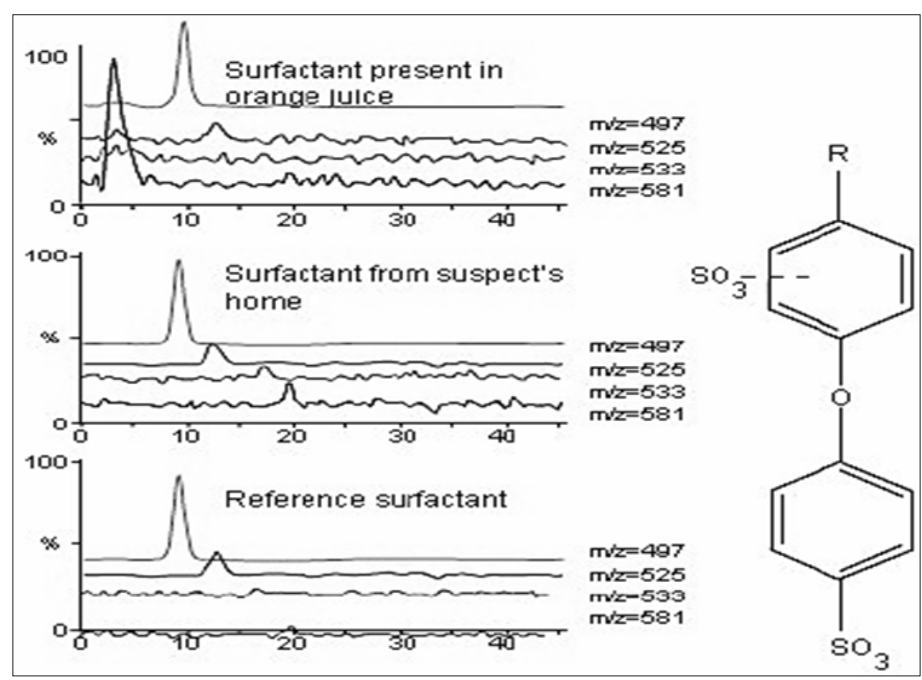

Figure 6: Extracted Ion Chromatogram of Orange Juice using LC-MS using ESI in negative mode.
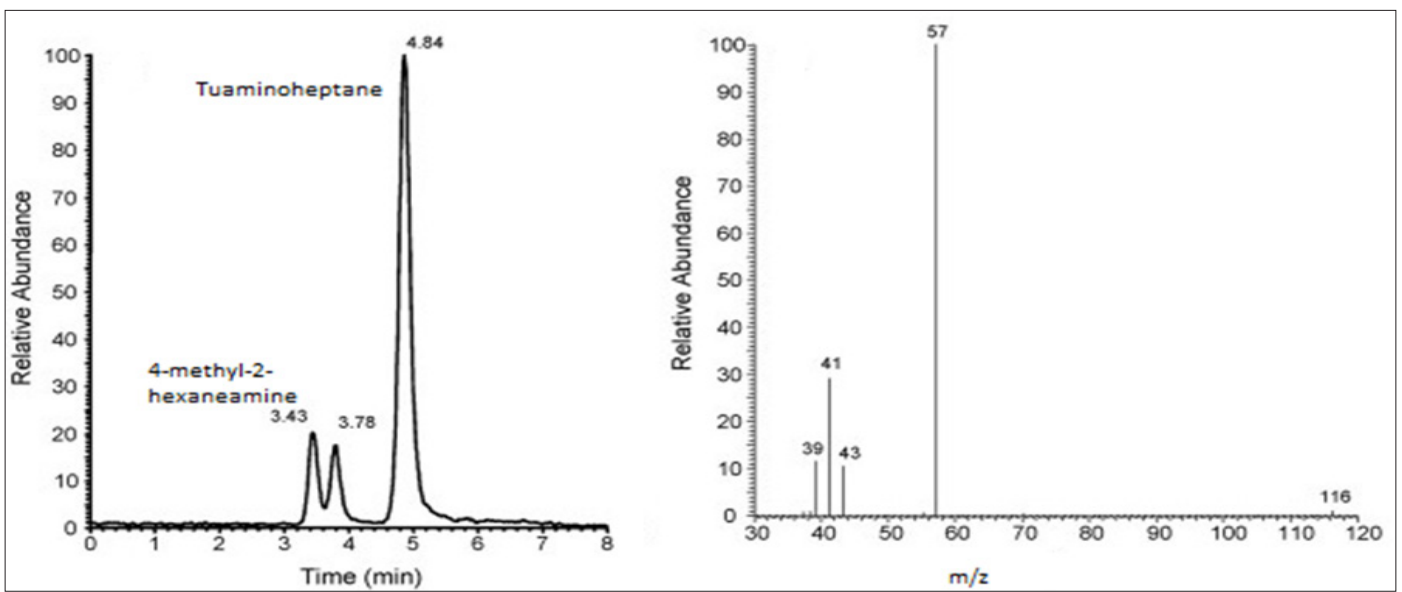

Figure 7: LC-MS Chromatogram in ESI $(+)$ of Tuaminoheptane and 4-methyl-2-hexaneamine and mass spectra of 4-methyl-2hexaneamine which shows pseudo molecular ions $[\mathrm{M}+\mathrm{H}]+$ at m/z 116 yield the prominent ion at m/z 57 . 


\section{Application of LC-MS in Doping Test:}

The LC/ESI-MS with positive mode can be used for detection in urine of 4-Methyl-2-hexaneamine doping agent. The urine samples are analysed with addition of internal standard of Tuaminoheptane. The suspected primary amine 4-methyl-2-hexaneamine, an analog contained in dietary supplement, to be the unknown compound. The standard used is 4-methyl-2-hexaneamine which exhibits two unresolved peaks at RT $3.43 \mathrm{~min}$ and $3.78 \mathrm{~min}$. which are identical with those of unknown compound [26]. The single reaction monitoring (m/z 116-57) was specific for detection of 4-methyl-2hexaneamine as shown below figure 7 .

\section{Other Applications:}

\section{In Pharmacokinetics:}

LC-MS is used in the study of absorption, metabolism, and excretion of drugs. Bio analytical methods are used for quantitative and structural elucidation of drugs and its metabolites in the biological samples (plasma, urine, saliva, serum etc.) [25].

\section{In Bioavailability and Bioequivalence study:}

Comparative bioequivalence studies in which quantitative determination of drugs or metabolites is measured in biological matrix, pharmacodynamics, clinical trials and In-vitro dissolution tests $[27,28]$.

\section{In determination of molecular weights:}

LC-MS is used for determination of molecular weights of known and unknown compounds. It provides the information about molecular weight, structure, identification, quantity of sample components. LC-MS is used for determination of molecular masses of proteins, nucleic acids, polymers and peptides.

\section{In determination of Assay of drug and intermediates:}

LC-MS is used in pharmaceutical industry for determination of assay of drug substances, drug products, intermediates and their related compounds [3].

\section{In Agrochemical and pesticides industry:}

It is used in determination of different components present in the fertilizers and pesticides [25].

\section{Environmental Applications:}

LC-MS is used for detection of phenyl urea herbicides, detection of low level of carbaryl in food [29].

\section{Literature Survey:}

Perrenoud L. developed LC-MS method for detection of 4-methyl-2-hexaneamine a doping agent from urine.LC-MS with ESI in positive mode is used. The analyte separated by gradient mobile phase on reverse phase $\mathrm{C} 8$ column.The single reaction monitoring ( $\mathrm{m} / \mathrm{z}$ 116-57) shows specific for detection of 4-methyl2-hexaneamine [26].
Allegrand J developed Atmospheric pressure photoionization (APPI) mass spectrometry of guanine using tunable synchrotron VUV radiation. In this APPI source coupled with tunable VUV photon source. The ionization of guanine occurred by chemical reactions, as a function of photon energy [13].

Pascual-Teresa Sd developed LC-MS method for analysis of anthocyanins from from purple corn cob. The nine different types of anthocyanins are isolated and identified by LC-MS. In this LC coupled with diode array spectrometry and mass spectrometry and determined the anthocyanins components from purple corn cob by fragmentation patterns (MS spectra) [30].

Wang Y developed LC-MS method for analysing total resveratrol in Grape juice, Cranberry juice and in wine. Samples were analysed by using reverse phase HPLC with positive ion atmospheric pressure chemical ionization (APCI) mass spectrometric detection. Resveratrol was detected in grape juice, cranberry juice and in wine, the concentration ranges from $1.56 \mathrm{nmol} / \mathrm{g}, 1.07 \mathrm{nmol} / \mathrm{g}$ and 8.63to $24.84 \mu \mathrm{mol} / \mathrm{L}$ respectively [31].

Chang-Kee L describes the current developments in LC-MS for pharmaceutical analysis. In this techniques like electrospray, atmospheric chemical ionization and photo ionization and their interfaces are discussed. The LC-MS application in drug discovery, in vitro and in vivo drug metabolism, identification, characterization of impurities in pharmaceutical analysis has been briefly discussed [1].

Nishikawa M reported the determination of surfactants by using LC-MS in forensic toxicity. The analysis of anionic, cationic and non-ionic surfactants are done in both negative and positive mode i.e. anionic surfactants and positive surfactants are detected as $\mathrm{M}$ - ions in the negative mode and $\mathrm{M}+$ ions in positive mode while non-ionic surfactants are in $[\mathrm{M}+\mathrm{H}]+$ ions or $[\mathrm{M}+\mathrm{NH} 4]+$ ions in positive mode. The recovery range obtained for anionic, cationic and non-ionic surfactants are $65.8 \%$ to $124 \%$ [32].

Hernando MD, determined the trace level of pharmaceutical residues in natural and treated water by using LC-MS. The samples like influent and effluent wastewaters, rivers and tap waters are analysed. The pharmaceuticals like Ibuprofen, Ketoprofen, and Diclofenac are determined at trace level by using solid -phase extraction (SPE) with liquid chromatography tandem mass spectrometry. The method detection limit and quantitation limit were 7.5-75 ng/L [33].

Souverain S developed the method for determination of protein precipitation for analysis of drug cocktail in plasma by using LC-ESI-MS. For protein precipitation (PP), Acetonitrile (ACN), perchloric acid (PA) and trichloroacetic acid (TCA) are used. The LC-ESI-MS method was developed for simultaneous analysis of six tested compounds in less than 6 minutes. Depending on the effective protein precipitation techniques to remove protein from human plasma and compatibility with LC-ESI-MS, ACN is used as PP 
technique in which recovery above $80 \%$ and $\mathrm{CV}$ up to $6 \%$ obtained [34].

Bogusz MJ , developed the LC-ESI-MS method for detection of synthetic adulterants in herbal remedies. Methanol is used for extraction of drugs and are separated by liquid chromatography with gradient mobile phase, Acetonitrile-10mM ammonium formate buffer $\mathrm{pH}$ 3.0. The limit of detection reported is $5 \mathrm{pg}$ to 1 ng per injection of sample. The recoveries of spiked drugs obtained are from 63 to $100 \%$ [35].

Roach AGS, describes the application of LC-MS/MS method for analysis for Acrylamide in foods. Acrylamide is used as internal standard. The limit of quantitation [13 C3] is 10ppb ( $\mu \mathrm{g} / \mathrm{kg})$. The method is applied to variety of foods. The variability in analyte level in food type helps to decrease the acrylamide in foods [36].

Jangala $\mathrm{H}$ developed and validated the LC-MS method for simultaneous estimation of Amlodipine and Valsartan in human plasma. The chromatographic separation achieved by using isocratic method using mobile phase as Acetonitrile: $5 \mathrm{mM}$ ammonium formate solution $(80: 20 \mathrm{v} / \mathrm{v})$, flow rate $0.8 \mathrm{~mL} / \mathrm{min}$. The quantitation was done using ESI in positive mode under multiple reactions monitoring (MRM) condition. Assay obtained in range $0.302-20.725 \mathrm{ng} / \mathrm{mL}$ for Amlodipine and 6.062-18060.792 $\mathrm{ng} / \mathrm{mL}$ ) for Valsartan [37].

\section{Conclusion}

The LC-MS is a hyphenated technique used in combination with separation power of HPLC with detection power of Mass spectrometry. It is widely used in pharmaceutical, chemical, food, agrochemical industries, environmental and forensic applications. LC-MS is used for qualitative and quantitative determination of drug substances and biological samples. Also it is commonly used in drug research and quality control.

\section{References}

1. Chang-Kee L (2002) Current Developments in LC-MS for Pharmaceutical Analysis. Biol Pharm Bull 25(5): 547-557.

2. Johnstone RAW, HerbertCG (2011) Mass Spectrometry Basics, CRC Press Boca Raton London New, United Kingdom.

3. Hanai T (1999) HPLC A Practical Guide, Health Research Foundation, Kyoto, Japan,Published by Royal Society of Chemistry, United Kingdom.

4. Snyder LR, Kirkland JJ, Glajch JL (1997) Practical HPLC method development. $2^{\text {nd }}(\mathrm{edn})$ Wiley Interscience Publication, John Wiley \& Sons Inc, Canada, pp. 205-215.

5. United States Pharmacopoeia, USP38 NF33, USA, pp. 519-525.

6. (2006) Liquid Chromatography-Mass Spectrometry Third Edition Wilfried MA Niessen hyphen MassSpec Consultancy Leiden, The Netherlands (C) 2006 by Taylor and Francis Group, LLC, p. 32-81.

7. Yergey AL, Edmonds CG, Lewis IAS, Vestal ML (1990) Liquid Chromatography/Mass Spectrometry: Techniques and Applications, CC Springer Science+Business Media New York, USA, p.5-7.

8. Iribarne JV, Thomson BA (1976) On the evaporation of small ions from charged droplets. J Chem Phys 64: 2287-2294.
9. Vogeser M (2003) Review Liquid Chromatography-Tandem Mass Spectrometry-Application in the Clinical Laboratory. Clin Chem Lab Med 41(2):117-126.

10. Kebarle $P$ (2000) A brief overview of the present status of the mechanisms involved in electroscopy mass spectrometry. J Mass Spectrum 35(7): 804-817.

11. Thomson BA, Ngo A (1983) Proceeding of the $31^{\text {st }}$ Annual Conference on Mass Spectrometry Allied Topics. Washington DC, USA, p. 65-66.

12. Covey TR, Bruins AP and Henion JD (1988) Comparison of Thermospray and Ion Spray Mass spectrometry in an Atmospheric Pressure Ion Source. Organic Mass Spectrometry 23(3): 178-181.

13. Allegrand J, Touboul D, Giuliani A, Brunelle A, Laprevote 0 (2012) Atmospheric pressure photoionization mass spectrometry of guanine using tunable synchrotron vuv radiation. International Journal Of Mass spectrometry 321-322: 14-18.

14. Kauppila TJ, Kotiaho T, Kostiainen R, Bruins AP (2004) Negative ionatmospheric pressure photoionization-Mass Spectrometry. Journal of American Society for Mass Spectrometry 15(2): 203-211.

15. Willoughby RC, Ross C Willoughby (1984) Monodisperse aerosol generation for combining liquid chromatography with mass spectrometry. Anal Chem 56(14): 2626-2631.

16. Shelke PG, Tripathi AS, Dewani AP, Bakal RL, Mohale DS, et al. (2012) Review Article Liquid Chromatography in conjunction with Mass Spectrometry (LC-MS). International Journal Of Pharmaceutical And Chemical Sciences 1(3): 1532-1538.

17. Barber M, Bordoli RS, Sedwick RD, Tyler AN (1981) Fast atom bombardment of solids (FAB): new ion source for mass spectrometry. J Chem Soc, Chem Commun 7: 325-327.

18. Pavia DL, Lampman GM, Kriz GS, Vyvyan JR Introduction to Spectroscopy, $5^{\text {th }}(\mathrm{edn}), \mathrm{pp} .120-122$.

19. Steel C, Michael Henchman (1998) Understanding the Quadrupole Mass Filter through Computer Simulation. J Chem Educ 75(8): 1049-1054.

20. Guilhaus M (1995) Special Feature: Tutorial, Principles and Instrumentation in Time-of-flight Mass Spectrometry, Physical and Instrumental Concepts. Journal Of Mass Spectrometry 30(11): 15191532.

21. Raymond EM, John FT (1995) Practical Aspects of Ion Trap Mass Spectrometry Volume-III, Chemical, Environmental and Biomedical Applications. By CRC Press, USA, Inc p. 4-19.

22. Raymond EM, John FJ Todd (1995) Special Feature: Tutorial an Introduction to Quadrupole Ion Trap Mass Spectrometry. Journal of Mass Spectrometry 32: 351-369.

23. Barnes IVJH, Hieftje GM (2004) Review Recent advances in detectorarray technology for mass spectrometry. International Journal of Mass Spectrometry 238(1): 33-46.

24. Kang JS (2012) Principles and Applications of LC-MS/Ms for the Quantitative Bioanalysis of Analytes in Various Biological Samples 441492.

25. Settle FA (2004) Handbook of Instrumental techniques for Analytical Chemistry. First Indian Reprint 569-660.

26. Perrenoud L, Saugy M, Saudan C (2009) Short communication Detection in urine of 4-methyl-2-hexaneamine, a doping agent. Journal of Chromatography 877(9): 3767-3770.

27. (2006) Definition of the main pharmacokinetic parameters.

28. Sargel L, Wu-Pongs, Yu ABC (2005) Applied Biopharmaceutics and Pharmacokinetics. $5^{\text {th }}$ (edn) Mc Graw-Hill, New York, USA, p. 5-9.

29. Hong Y, Barrett DM, Mitchell AE (2004) Liquid Chromatography/Mass Spectrometry Investigation of the Impact of Thermal Processing and 
Storage on Peach Procyanidins. Journal of Agricultural Food Chemistry 52(8): 2366-2371.

30. Pascual-Teresa SD, Santos-Buelga C, Rivas-Gonzalo JC (2002) LC-MS analysis of anthocyanins from purple corn cob. Journal of Science of the Food and Agriculture 82(9): 1003-1006.

31. Wang Y, Catana F, Yang Y, Roderick R, van Breemen RB (2002) An LC-MS Method for Analyzing Total Resveratrol in Grape Juice, Cranberry Juice, and in Wine. J Agric Food Chem 50(3): 431-435.

32. Nishikawa M, Katagi M, Miki A, Tsuchihashi H (2003) Forensic Toxicological Determination of Surfactant by Liquid Chromatography/ Electrospray Ionization Mass Spectrometry and Liquid Chromatography/ Electrospray Ionization Tandem Mass Spectrometry. Journal of Health Science 49(2): 138-148.

33. Hernando MD, Heath E, Petrovic M, Barceló D (2006) Trace-level determination of pharmaceutical residues by LC-MS/MS in natural and treated waters. A pilot-survey study. Analytical and Bio analytical Chemistry 385(6): 985-991.
34. Souverain S, Rudaz S, Veuthey JL (2004) Protein precipitation for the analysis of a drug cocktail in plasma by LC-ESI-MS. Journal of Pharmaceutical and Biomedical Analysis 35(4): 913-920.

35. Bogusz MJ, Hassan H, Al-Enazi E, Ibrahim Z, Al-Tufail M (2006) Application of LC-ESI-MS-MS for detection of synthetic adulterants in herbal remedies. Journal of Pharmaceutical and Biomedical Analysis 41(2): 554-564.

36. Roach JAG , Andrzejewski D, Gay ML, Nortrup D, Musser SM (2003) Rugged LC-MS/MS Survey Analysis for Acrylamide in Foods. J Agric Food Chem 51(26): 7547-7554.

37. Jangala H, Vats P, Khuroo AH, Monif T (2014) Development and Validation of a LC-MS/MS Method for the Simultaneous Estimation of Amlodipine and Valsartan in Human Plasma: Application to a Bioequivalence Study. ScientiaPharmaceutica 82(3): 585-600.

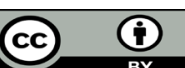

This work is licensed under Creative Commons Attribution 4.0 License

Submission Link: Submit Article

DOI: 10.32474/AOICS.2018.01.000103

\section{AOICS}

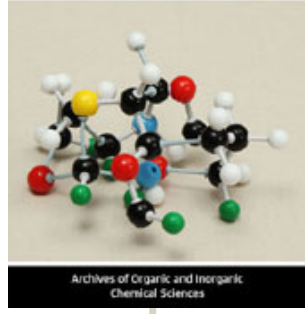

Archives of Organic and Inorganic Chemical Sciences

\section{Assets of Publishing with us}

- Global archiving of articles

- Immediate, unrestricted online access

- Rigorous Peer Review Process

- Authors Retain Copyrights

- Unique DOI for all articles 